\title{
Novel route of synthesis of Sn-coated SBA-15
}

\author{
Marek Kosmulski ${ }^{1} \cdot$ Edward Mączka $^{1}$
}

Published online: 3 October 2018

(c) The Author(s) 2018

\begin{abstract}
A series of Sn-modified SBA-15, was studied. On top of Sn-only modified materials, several materials were modified with $\mathrm{Sn}$ and then Ti or with $\mathrm{Sn}$ and then Al. The new materials were obtained by adsorption of vapors of metal chlorides on SBA-15 (at 30-110 ${ }^{\circ} \mathrm{C}$ ), and hydrolysis of adsorbed chlorides by water vapor at $25^{\circ} \mathrm{C}$, and then evaporation of left-overs of volatile compounds at $140^{\circ} \mathrm{C}$. The Sn-modified SBA- 15 had lower specific surface area, and a higher thermal stability than the original silica. Even in materials containing substantial amount of $\mathrm{Sn}$, the presence of crystalline phases representing $\mathrm{Sn}$ compounds was not detected by XRD. In contrast, rutile and anatase were observed in Sn- and Ti-modified SBA-15 while crystalline phases representing Ti compounds were not detected when Ti was deposited directly on SBA-15 (not modified with Sn). The profiles of Sn concentration across the particles of Sn-modified SBA-15 indicate that Sn is located in the pores rather than on the external surface.
\end{abstract}

Keywords Silica $\cdot$ Tin oxide $\cdot$ Rutile $\cdot$ Anatase $\cdot$ Specific surface area $\cdot \zeta$ Potential

\section{Introduction}

Mesoporous silicas modified with metals have been extensively studied for many decades, and tin is among the metals, most frequently used to modify porous silicas. Introduction of MCM-41 [1], SBA-15 [2] and of other well-defined and high-specific-surface-areas (SSAs) silicas in the 1990s increased the interest in metal-modified silicas. Typically Sn-modified silicas are obtained by impregnation of the support with solution of soluble Sn compound [3] followed by drying and calcination. The interest in metal-modified porous silicas peaked in the beginning of this century, and now it is slowly declining, but $\mathrm{Sn}$-modified porous silicas remain an active field, especially in view of their catalytic properties.

Very recently $\mathrm{Li}$ et al. [4] obtained composites with $0.4-1.6 \% \mathrm{Sn}$ by mass by addition of $\mathrm{SnCl}_{2}$ to $\mathrm{P} 123-\mathrm{HCl}$ solution in course of a standard SBA-15 synthesis, and their composites had slightly lower SSA and total pore volume

Marek Kosmulski

marek@kosmulski.org

Edward Mączka

e.maczka@pollub.pl

1 Lublin University of Technology, Nadbystrzycka 38A,

20-618 Lublin, Poland than the SBA-15 without tin obtained by the same method. They also studied a Sn-modified specimen obtained by incipient wetness impregnation, and their materials were used as supports for Pt-catalysts for propane dehydrogenation.

Pang et al. [5] obtained composites with Si/Sn molar ratios from 130 to 394 by impregnation of SBA-15 with ethanolic solution of $\mathrm{SnCl}_{4}$ pentahydrate. Their composites had slightly lower SSA and identical total pore volume as the original SBA-15. They also studied a Sn-modified specimen obtained by incipient wetness impregnation, and their materials were used as catalysts for conversion of carbohydrates to methyl lactate.

$\mathrm{Xu}$ et al. [6] obtained composites with $\mathrm{Si} / \mathrm{Sn}$ ratios of 13 and 53 by impregnation of SBA- 15 with solution of dimethyldichlorostannate and of trimethylamine in $p$-xylene followed by washing, and then by calcination in oxygen. Their composites had substantially lower SSA than the original SBA-15 in spite of low Sn fraction. Their materials were used as catalysts for hydrogenation of levulinic acid to $\gamma$-valerolactone.

Skoda et al. [7] obtained composites with $43 \%$ Sn by mass by addition of tetrakis(diethylamido)tin to Si-precursor in course of synthesis, and they studied catalytic performance of their composite material in aminolysis of styrene oxide with aniline. 
Chen et al. [8] obtained composites with $\mathrm{Si} / \mathrm{Sn}$ ratios from 21 to 132 by addition of $\mathrm{SnCl}_{4}$ to $\mathrm{P} 123-\mathrm{HCl}$ solution in course of a standard SBA-15 synthesis, and they also obtained Sn-modified MCM-41. The Sn-modified SBA-15 had slightly lower SSA and total pore volume than the SBA15 without tin, and the Sn-modified MCM-41 had substantially lower SSA and total pore volume than the MCM-41 without tin obtained by the same method. Their materials were used as catalysts for oxidation of cyclohexanone to $\varepsilon$-caprolactone.

Srinivasan et al. [9] obtained composites with 5-17\% Sn by impregnation of five different lots of SBA- 15 with dilute aqueous $\mathrm{SnCl}_{4}$ solution followed by reduction with solution of sodium borohydride. The product was filtered out, washed with water, and oxidized at $100{ }^{\circ} \mathrm{C}$ in air. Their materials were used as catalysts for photochemical degradation of rhodamine B.

In view of their extraordinary catalytic properties, Sn-porous silica composites deserve special attention. In this study we present a novel method of preparation of such composites, which is based on our previous experiments with other metals $[10,11]$. Namely in contrast with other studies which used one-pot synthesis ( $\mathrm{Sn}$ precursor added in course of synthesis of porous silica) or post-synthesis impregnation of porous silica with solution of Sn precursor, we deposited volatile metals or volatile metal compounds on pre-synthesized silica. Our method can be used to deposit practically every metal, but so far we only presented composites containing $\mathrm{Cd}, \mathrm{Zn}, \mathrm{Ti}$ and $\mathrm{Al}$. In this study we focus on Sn-modified SBA-15. With its boiling point at $114{ }^{\circ} \mathrm{C}$, and vapor pressure of $24 \mathrm{hPa}$ at $20^{\circ} \mathrm{C}$, tin(IV) chloride is a convenient precursor of tin, which can be deposited on silica from gas phase even at room temperature.

\section{Methods}

\subsection{Deposition of Sn, Al and Ti on SBA-15}

We used the same lot of SBA-15 (produced using a standard recipe) as in our previous work [11]. Silica was stored for 6-9 months in a plastic bottle before deposition of Sn. The method of deposition of metals onto silica by adsorption of vapors of their chlorides and then their hydrolysis is similar to that described in older literature [12]. A portion of 90-250 mg of SBA-15, was transferred into a 15-mL glass beaker, and 90-210 mg of anhydrous metal chloride was transferred into another $15-\mathrm{mL}$ beaker. The beakers were closed in an air-tight $300 \mathrm{~mL}$ glass flask. These operations were performed as quickly as possible to avoid reaction between anhydrous chlorides and atmospheric moisture. The closed conical flask with both beakers was thermostated in a laboratory drying oven at certain temperature, and for certain time, and then cooled down to room temperature. Two different geometries produced different composites at otherwise identical conditions. In geometry 1 (most experiments) the $15 \mathrm{~mL}$ beakers were broad and short, and in geometry 2 (a few experiments) they were narrow and tall. The SBA-15 with metal chloride adsorbed on it, was allowed to react with vapor of $2 \mathrm{M} \mathrm{KOH}$ for 1 day in a desiccator, and it was dried for 1 day at $140{ }^{\circ} \mathrm{C}$. A few materials were dried at lower temperatures after hydrolysis, but the low drying temperature was proved insufficient for complete removal of volatile compounds in Sn-rich composites (see Results section for more detail). The amount of metal oxide deposited on silica was determined on mass basis. Several Sn-SBA-15 composites were further processed as described above, but with $\mathrm{TiCl}_{4}$ (deposition at $30-50{ }^{\circ} \mathrm{C}$ ) or with $\mathrm{AlCl}_{3}$ (deposition at $110^{\circ} \mathrm{C}$ ) as metal precursors. A few composites were heated at $600-1000{ }^{\circ} \mathrm{C}$ to test their thermal stability.

\subsection{Characterization of Sn-modified SBA-15}

XRD patterns of the composites were collected with Empyrean from PANalytical. The BET SSA and pore volume were measured with Gemini V (Micromeritics). A few composites were dispersed in $10^{-3} \mathrm{M} \mathrm{NaCl}$ to measure the $\zeta$ potential and particle size as a function of $\mathrm{pH}$ by means of Malvern Zetasizer (Malvern, UK). Tecnai $G^{2} 20$ from FEI (Hillsboro, Oregon) was used to obtain microscopic images of the original and Sn-modified SBA-15 containing $38.75 \%$ of $\mathrm{SnO}_{2}$ by mass $\left(\mathrm{SiO}_{2}=100 \%\right)$. This material was obtained by adsorption of tin chloride at $50{ }^{\circ} \mathrm{C}$ for $1 \mathrm{~h}$, and it has a SSA of $650.5 \mathrm{~m}^{2} \mathrm{~g}^{-1}$. The ethanolic dispersion of pulverized material was ultrasonified, and deposited on Lacey $\mathrm{C} / \mathrm{F}$ polymer-coated $\mathrm{Cu}$ grid. The images in bright field mode with CCD detector, and in STEM mode with HAADF detector were recorded. Concentration profiles of $\mathrm{O}, \mathrm{Si}$, and $\mathrm{Sn}$ across a particle of the same Sn-modified SBA-15 were studied using TEM-EDS (energy dispersive $\mathrm{X}$-ray spectroscopy) method.

\section{Results and discussion}

\subsection{Original and calcined SBA-15}

The calcination of SBA- 15 at temperatures below $700{ }^{\circ} \mathrm{C}$ had rather insignificant effect on its properties, while modification at temperatures above $700{ }^{\circ} \mathrm{C}$ resulted in decrease in the SSA and in the pore volume. The detailed results are presented elsewhere [11], and they are in line with numerous results reported in the literature. 


\subsection{Preparation of Sn-modified SBA-15}

The specimens of Sn-modified SBA-15 after hydrolysis of adsorbed $\mathrm{SnCl}_{4}$ were dried at various temperatures in order to establish the conditions necessary to completely remove the volatile compounds from silica. The specimens underwent $1 \mathrm{~h}$ drying cycles at 80 , then 90 , then 100 , then 110 , and then $120^{\circ} \mathrm{C}$, followed by $20 \mathrm{~h}$ at $130^{\circ} \mathrm{C}$ and $24 \mathrm{~h}$ at $140{ }^{\circ} \mathrm{C}$. The decrease in mass of two specimens of Snmodified SBA-15 (17 and $15 \% \mathrm{SnO}_{2}$ by mass, respectively) on drying is illustrated in Fig. 1. These results show that even after 20-h drying at $130^{\circ} \mathrm{C}$ the process of removal of volatile compounds was not $100 \%$-complete. Therefore all specimens were dried for at least 1 day at $140{ }^{\circ} \mathrm{C}$ in order to completely remove volatile compounds. Figure 1 illustrates the behavior of the components with high Sn concentration. In specimens with low (e.g., $3 \%$ ) $\mathrm{SnO}_{2}$ concentration already drying at $90{ }^{\circ} \mathrm{C}$ for $1 \mathrm{~h}$ led to complete removal of volatile compounds, that is, further heating at $100,110^{\circ} \mathrm{C}$, etc. had

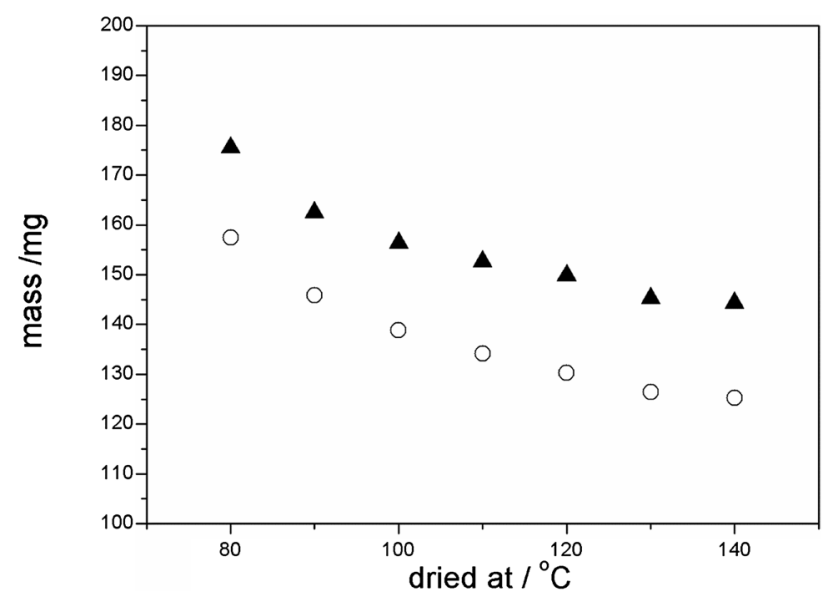

Fig. 1 Mass of two specimens of Sn-modified SBA-15 (white circles $17 \% \mathrm{SnO}_{2}$, black triangles $15 \% \mathrm{SnO}_{2}$ ) dried at various temperatures after hydrolysis of $\mathrm{SnCl}_{4}$ rather insignificant effect on the mass of the composite. Also in Ti- and Al-modified SBA-15 (discussed in detail in our previous study [11]), drying at $90{ }^{\circ} \mathrm{C}$ for $1 \mathrm{~h}$ was sufficient to completely remove volatile compounds.

\subsection{Sn-modified SBA-15}

The properties of Sn-modified SBA-15, obtained by deposition of $0.1 \mathrm{~mL}$ of $\mathrm{SnCl}_{4}$ for $30 \mathrm{~min}$ at $30-50{ }^{\circ} \mathrm{C}$ in different geometries (see experimental) on (about) $100 \mathrm{mg}$ of SBA- 15 are summarized in Tables 1 and 2 . The specimens presented in Table 2 are different than those presented in Table 1, and they were further modified with Ti or with Al.

Preparation at the same conditions (amount of $\mathrm{SnCl}_{4}$, time and temperature of deposition, geometry) produced materials with similar fraction of $\mathrm{SnO}_{2}$ (with substantial scatter).

The presence of Sn in SBA-15 resulted in linear decrease in the SSA of silica (correlation coefficient of 0.92) with the mass fraction of $\mathrm{SnO}_{2}$. The micropore volume was rather insensitive to the presence of $\mathrm{Sn}$, and it showed random scatter rather than systematic trend when plotted against the amount of $\mathrm{SnO}_{2}$. The correlation between SSA and the amount of $\mathrm{SnO}_{2}$ in the composite is presented in Fig. 2.

The XRD patterns of Sn-modified SBA-15 are shown in Figs. 3 and 4. The small angle XRD patterns (Fig. 3) indicate the hexagonal structure in Sn-SBA-15, and the presence of Sn had rather insignificant effect on the $d$-spacing. The wide-angle XRD patterns of Sn-modified SBA-15 (Fig. 4) did not reveal any peaks representing Sn-compounds in spite of substantial mass fraction of $\mathrm{Sn}$ in the composite materials. Apparently Sn occurs in the composite as a thin uniform layer on the surface of silica rather than as large crystalline aggregates. There is a shoulder in the XRD pattern of the specimen containing $26 \%$ of $\mathrm{SnO}_{2}$, at $2 \theta$ of about $10^{\circ}$ which does not occur in other patterns, but this feature does not prove the presence of crystalline Sn compound(s).
Table 1 Properties of Sn-modified SBA-15

\begin{tabular}{|c|c|c|c|c|c|c|c|}
\hline \multicolumn{3}{|c|}{ Adsorption of $\mathrm{SnCl}_{4}$} & \multirow{2}{*}{$\begin{array}{l}\% \mathrm{SnO}_{2} \\
\left(\mathrm{SiO}_{2}=100 \%\right)\end{array}$} & \multirow[t]{2}{*}{$\operatorname{SSA}\left(\mathrm{m}^{2} \mathrm{~g}^{-1}\right)$} & \multirow{2}{*}{$\begin{array}{l}\text { Pore } \\
\text { volume } \\
\left(\mathrm{cm}^{3} \mathrm{~g}^{-1}\right)\end{array}$} & \multirow{2}{*}{$\begin{array}{l}\text { Micropore } \\
\text { volume } \\
\left(\mathrm{cm}^{3} \mathrm{~g}^{-1}\right)\end{array}$} & \multirow{2}{*}{$\begin{array}{l}\text { Average pore } \\
\text { diameter }(\mathrm{nm})\end{array}$} \\
\hline$t\left({ }^{\circ} \mathrm{C}\right)$ & Time (h) & geometry & & & & & \\
\hline None & & & None & 910.1 & 1.035 & 0.104 & 4.55 \\
\hline 30 & 0.5 & 1 & 26.4 & 694.7 & 0.83 & 0.078 & 4.78 \\
\hline 30 & 0.5 & 1 & 10.4 & 791.5 & 0.933 & 0.095 & 4.72 \\
\hline 30 & 0.5 & 1 & 11.7 & 777.5 & 0.929 & 0.091 & 4.78 \\
\hline 30 & 0.5 & 1 & 16.1 & 761.6 & 0.923 & 0.092 & 4.85 \\
\hline 30 & 0.5 & 2 & 4.1 & 881.7 & 1.015 & 0.11 & 4.61 \\
\hline 30 & 0.5 & 2 & 5.3 & 846.9 & 0.991 & 0.107 & 4.68 \\
\hline 35 & $0.5^{\mathrm{a}}$ & 1 & 10.9 & 733.4 & 0.915 & 0.082 & 4.99 \\
\hline
\end{tabular}

a $226 \mathrm{mg}$ of SBA-15 
Table 2 Properties of Ti-modified Sn-SBA-15 and of Al-modified Sn-SBA-15

\begin{tabular}{|c|c|c|c|c|c|c|c|}
\hline \multicolumn{2}{|c|}{ First deposition } & \multicolumn{2}{|c|}{ Second deposition } & \multirow[t]{2}{*}{$\operatorname{SSA}\left(\mathrm{m}^{2} \mathrm{~g}^{-1}\right)$} & \multirow{2}{*}{$\begin{array}{l}\text { Pore volume } \\
\left(\mathrm{cm}^{3} \mathrm{~g}^{-1}\right)\end{array}$} & \multirow{2}{*}{$\begin{array}{l}\text { Micropore volume } \\
\left(\mathrm{cm}^{3} \mathrm{~g}^{-1}\right)\end{array}$} & \multirow{2}{*}{$\begin{array}{l}\text { Average pore } \\
\text { diameter (nm) }\end{array}$} \\
\hline Metal & $\begin{array}{l}\% \text { of metal oxide } \\
\left(\mathrm{SiO}_{2}=100 \%\right)\end{array}$ & Metal & $\begin{array}{l}\% \text { of metal oxide } \\
\left(\mathrm{SiO}_{2}=100 \%\right)\end{array}$ & & & & \\
\hline None & None & None & None & 910.1 & 1.035 & 0.104 & 4.55 \\
\hline $\mathrm{Sn}$ & 10.4 & None & None & 791.5 & 0.933 & 0.095 & 4.72 \\
\hline $\mathrm{Sn}$ & 10.4 & $\mathrm{Ti}$ & 27.6 & 595.2 & 0.613 & 0.085 & 4.12 \\
\hline $\mathrm{Sn}$ & 11.7 & None & None & 777.5 & 0.929 & 0.091 & 4.78 \\
\hline $\mathrm{Sn}$ & 11.7 & $\mathrm{Ti}$ & 17.7 & 611.7 & 0.678 & 0.081 & 4.43 \\
\hline $\mathrm{Sn}$ & 16.1 & None & None & 761.6 & 0.923 & 0.092 & 4.85 \\
\hline $\mathrm{Sn}$ & 16.1 & $\mathrm{Ti}$ & 8.3 & 746 & 0.977 & 0.082 & 5.24 \\
\hline $\mathrm{Sn}$ & 14.9 & None & None & 667 & 0.813 & 0.07 & 4.88 \\
\hline Sn & 14.9 & $\mathrm{Ti}$ & 25.9 & 549.3 & 0.636 & 0.059 & 4.63 \\
\hline $\mathrm{Sn}$ & 17.2 & None & None & 706.3 & 0.853 & 0.073 & 4.83 \\
\hline $\mathrm{Sn}$ & 17.2 & $\mathrm{Ti}$ & 37.2 & 546 & 0.624 & 0.064 & 4.57 \\
\hline $\mathrm{Sn}$ & 2.9 & None & None & 833.7 & 0.956 & 0.104 & 4.59 \\
\hline $\mathrm{Sn}$ & 2.9 & $\mathrm{Ti}$ & 3 & 833.2 & 0.975 & 0.104 & 4.68 \\
\hline Sn & 19.9 & None & None & 710 & 0.891 & 0.064 & 5.02 \\
\hline $\mathrm{Sn}$ & 19.9 & $\mathrm{Al}$ & 11.7 & 708.3 & 0.907 & 0.07 & 5.12 \\
\hline $\mathrm{Sn}$ & 15.2 & None & None & 716.9 & 0.873 & 0.075 & 4.87 \\
\hline $\mathrm{Sn}$ & 15.2 & $\mathrm{Al}$ & 14 & 718.2 & 0.933 & 0.079 & 5.19 \\
\hline $\mathrm{Sn}$ & 20.7 & None & None & 641.9 & 0.813 & 0.061 & 5.06 \\
\hline $\mathrm{Sn}$ & 20.7 & $\mathrm{Al}$ & 4.7 & 670.2 & 0.82 & 0.068 & 4.89 \\
\hline
\end{tabular}

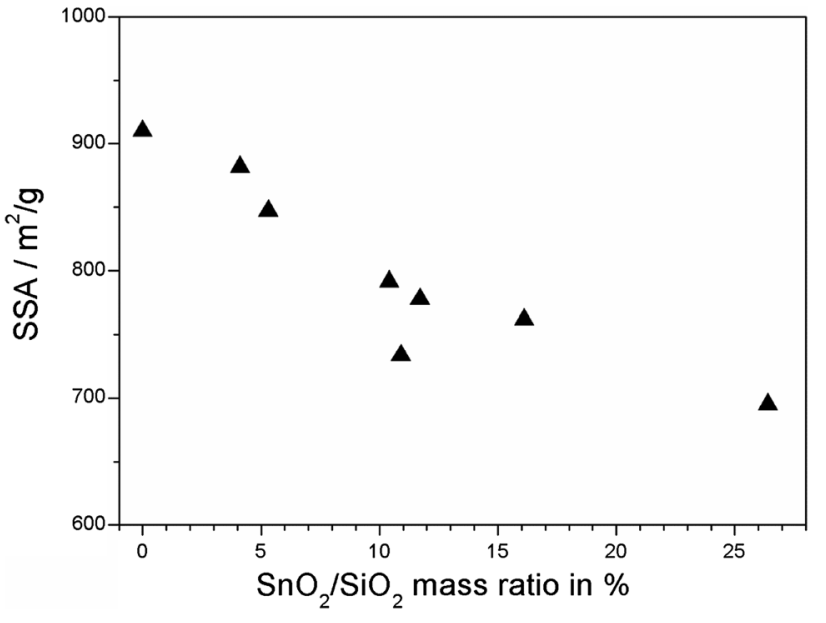

Fig. 2 Correlation between the amount of deposited $\mathrm{SnO}_{2}$ and the specific surface area of Sn-modified SBA-15

\subsection{Thermal stability}

Figure 5 shows the result of calcination at different temperatures on the SSA of a Sn-modified material containing $11 \%$ of $\mathrm{SnO}_{2}$. The calcination at temperatures up to $800{ }^{\circ} \mathrm{C}$ had rather insignificant effect on the SSA while calcination at higher temperatures depressed the SSA. Apparently Snmodified SBA-15 is more resistant to calcination than the

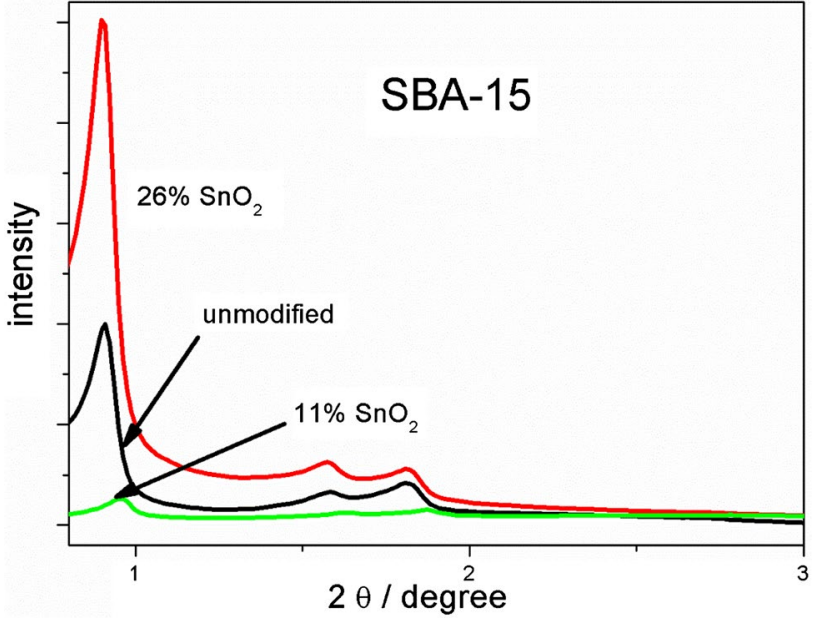

Fig. 3 Small-angle XRD patterns of original and of Sn-modified SBA-15

original SBA-15 (Sect. 3.1), but temperatures above $800{ }^{\circ} \mathrm{C}$ cause degradation of both modified and unmodified silica.

\subsection{Sn- and Ti-modified SBA-15 and Sn- and Al-modified SBA-15}

Several materials were obtained using $\mathrm{AlCl}_{3}$ to deposit alumina, and $\mathrm{TiCl}_{4}$ to deposit titania on Sn-SBA-15 (obtained 


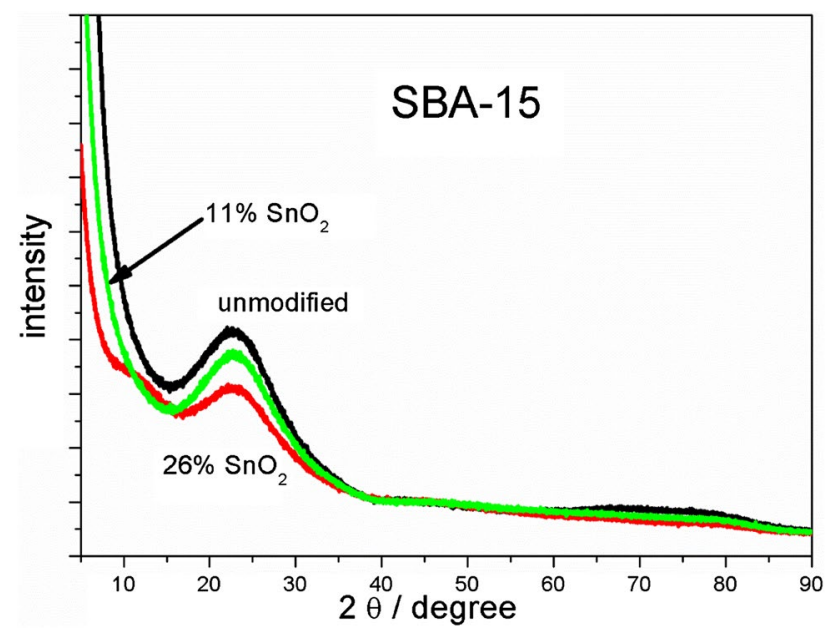

Fig. 4 Wide-angle XRD patterns of original and of Sn-modified SBA-15

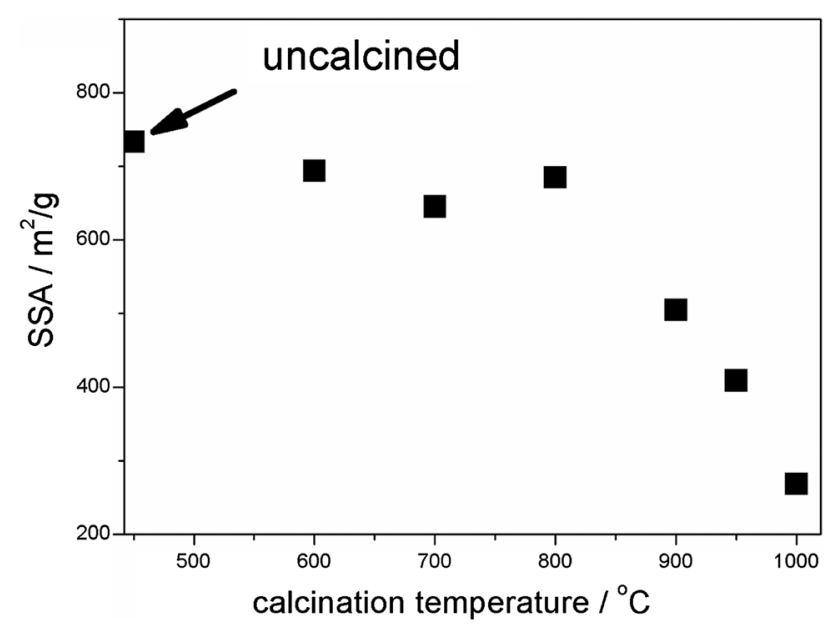

Fig. 5 The effect of calcination temperature on the SSA of a Sn-modified SBA-15 containing $11 \%$ of $\mathrm{SnO}_{2}$

according to the procedure described in the experimental part). Materials with Sn deposited on Al-SBA-15 or on TiSBA-15 were not studied. The method of deposition of $\mathrm{Ti}$ and $\mathrm{Al}$ was similar to the method used for deposition of $\mathrm{Sn}$, and it was described in more detail in our previous paper [11]. The properties of the original SBA-15, of Sn-SBA-15 which were used as supports, and of the final products ( $\mathrm{Sn}$ and Ti-modified SBA-15 and Sn- and Al-modified SBA15) are summarized in Table 2 . The Sn-SBA- 15 presented in Table 2 are different specimens from those presented in Table 1. Most Sn-SBA-15 were obtained by deposition of $\mathrm{SnCl}_{4}$ at 30 or $35^{\circ} \mathrm{C}$, and in the specimen with $15.2 \% \mathrm{SnO}_{2}$ the deposition was at $40{ }^{\circ} \mathrm{C}$, and in the specimens with 19.9 and $20.7 \% \mathrm{SnO}_{2}$ the deposition was at $50{ }^{\circ} \mathrm{C}$. The properties of supports (Sn-only-SBA-15) are followed by the properties of the final products (Sn- and Ti-SBA-15 and Sn- and AlSBA-15) obtained from these supports.

$\mathrm{TiCl}_{4}$ and $\mathrm{AlCl}_{3}$ are adsorbed onto Sn-modified silicas to similar degree as onto the original SBA-15, that is, the mass $\%$ of titania or of alumina in materials obtained from Sn-modified silicas is similar as in materials obtained from the original SBA-15 at the same conditions (amount of metal chloride, time and temperature of deposition).

The modification of SBA-15 with metals resulted in nearly linear decrease in the SSA of silica (correlation coefficient of 0.89 ) with the total amount of metal oxides, and the micropore volume decreased on Ti-modification. The correlation between SSA and the amount of metal oxides is illustrated in Fig. 6. The slope of the trend line (about $10 \mathrm{~m}^{2} \mathrm{~g}^{-1}$ per $1 \%$ of metal oxide) in Fig. 6 is similar to that observed in Fig. 2. As we discussed in our previous papers, the decrease in the SSA $\left(\mathrm{m}^{2} \mathrm{~g}^{-1}\right)$ is in line with the specific density of tin $\left(7 \mathrm{~g} \mathrm{~cm}^{-3}\right)$ and of titanium and aluminum $\left(4 \mathrm{~g} \mathrm{~cm}^{-3}\right)$ oxides, which is substantially higher than that of silica.

The small angle XRD pattern of SBA-15 was rather insensitive to the $\mathrm{Sn}$ - and Ti-modification as illustrated in Fig. 7. It indicates the hexagonal structure in Sn- and TiSBA-15, and the presence of Sn and Ti had rather insignificant effect on the $d$-spacing. The wide-angle XRD pattern of Sn- and Ti-modified SBA-15 (Fig. 8) did not reveal any peaks representing Sn-compounds, and this result suggests that tin is present in the composite as a thin, uniform layer on the surface of silica. This result is in line with the results observed with Sn-only modified SBA-15 (Fig. 4).

Crystallization of titanium dioxide was observed on Snmodified SBA-15. This result is different from the results reported in [11], in which no peaks corresponding to Ticompounds were observed in materials obtained by the same

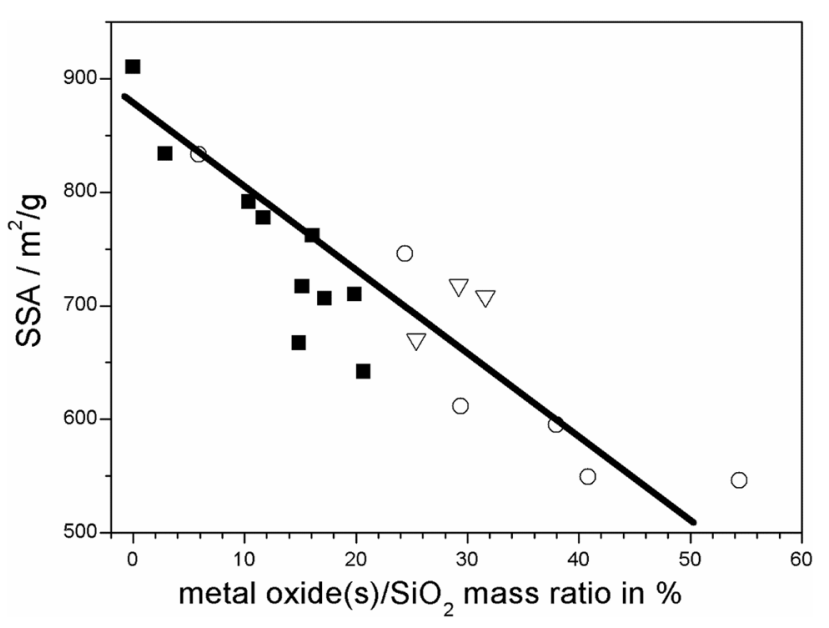

Fig. 6 Correlation between the total amount of metal oxide(s) and the specific surface area of Sn-modified SBA-15 (black squares) of Snand Ti-modified SBA-15 (white circles), and of Sn- and Al-modified SBA-15 (white triangles) 


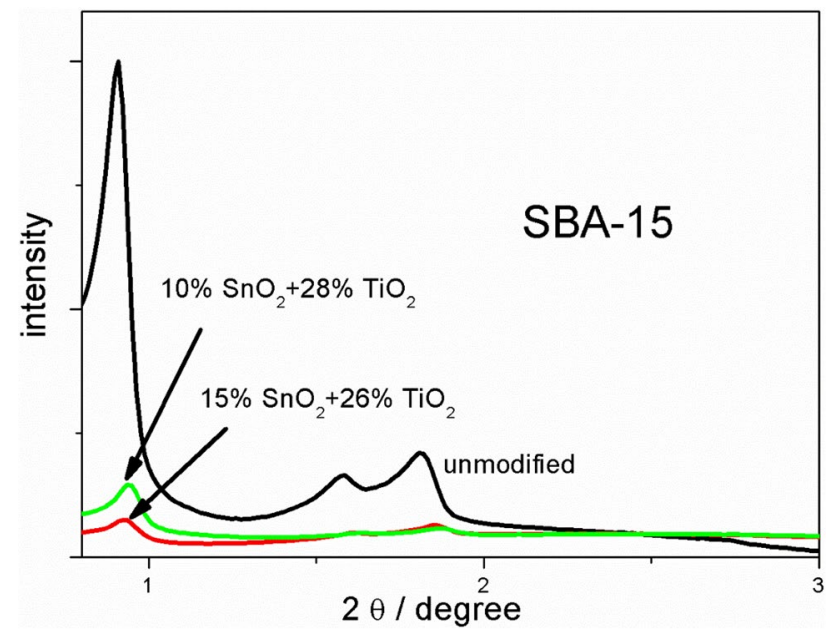

Fig. 7 Small-angle XRD patterns of Sn- and Ti-modified SBA-15 as compared with the original silica

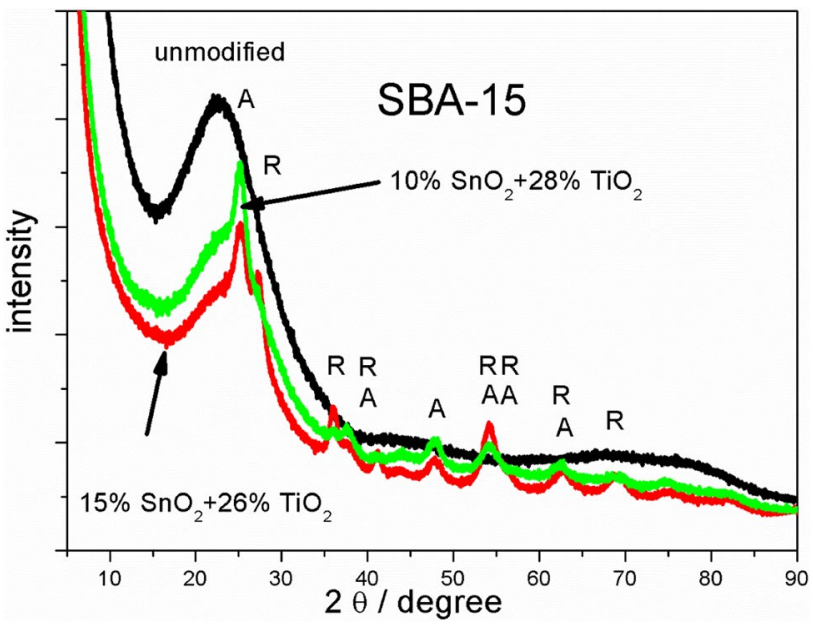

Fig. 8 Wide-angle XRD patterns of Sn- and Ti-modified SBA-15 as compared with the original silica. $A$ anatase, $R$ rutile

method as used in the present study, when Ti was deposited directly on SBA-15 or on Al-modified SBA-15. The peaks corresponding to Ti-compounds were not observed in Timodified SBA-15 even after calcination at $700{ }^{\circ} \mathrm{C}$. Apparently the presence of $\mathrm{Sn}$ on the surface of SBA-15 promoted crystallization of titania in Sn- and Ti-modified materials. Cassiterite $\left(\mathrm{SnO}_{2}\right)$ is isostructural with rutile, and this may explain the difference in crystallization of $\mathrm{TiO}_{2}$ on $\mathrm{Sn}$ SBA- 15 on the one hand and on bare SBA- 15 on the other. Almost pure anatase with a small admixture of rutile was observed in the specimen containing $10 \%$ of $\mathrm{SnO}_{2}$ and $28 \%$ of $\mathrm{TiO}_{2}$, while a 42:58 anatase-rutile mixture was observed in the specimen containing $15 \%$ of $\mathrm{SnO}_{2}$ and $26 \%$ of $\mathrm{TiO}_{2}$. We also attempted to determine the sizes of crystallites from FWHM of the peaks shown in Fig. 8. The apparent sizes of crystallites determined from the $25^{\circ}$ peak (anatase) and $27.5^{\circ}$ peak (rutile) were $8 \mathrm{~nm}$ in the specimen containing $10 \%$ of $\mathrm{SnO}_{2}$ and $28 \%$ of $\mathrm{TiO}_{2}$ and $9 \mathrm{~nm}$ in the specimen containing $15 \%$ of $\mathrm{SnO}_{2}$ and $26 \%$ of $\mathrm{TiO}_{2}$. This should be emphasized that most peaks observed in anatase-rutile mixtures are results of overlap of two or more lines (from both rutile and anatase) and they are of limited significance in crystallite size determination. The crystallization of titania in Ti-modified SBA-15 was discussed in many previous studies. However, in most studies the Ti-modified SBA-15 was calcined before the XRD study, and the structure of uncalcined materials was not reported. For example Landau et al. [13] observed anatase in Ti-modified SBA-15 obtained by impregnation of porous silica with Ti-butoxide, followed by chemical solution decomposition or by internal hydrolysis, and by calcination at $500^{\circ} \mathrm{C}$. Acosta-Silva et al. [14] observed anatase in Ti-modified SBA-15 obtained by impregnation of porous silica with propanolic solution of Ti-isopropoxide, followed by addition of water at room temperature, and by calcination at $550{ }^{\circ} \mathrm{C}$. Anatase was only observed in Ti-rich specimens ( $26 \%$ of titania or more). In contrast with most previous studies, our specimens were not calcined, and they were only dried at $140{ }^{\circ} \mathrm{C}$.

The deposition of $\mathrm{Al}$ on Sn-SBA-15 resulted in rather insignificant change in the SSA, and in one specimen the SSA even increased on Al-deposition.

\subsection{TEM images and concentration profiles}

The bright-field TEM image of Sn-modified SBA-15 containing $39 \%$ of $\mathrm{SnO}_{2}\left(\mathrm{SiO}_{2}=100 \%\right)$ by mass (Fig. 9) confirms the typical structure reported in the literature for unmodified and metal-modified SBA-15 materials. The feature in the upper right part shows a hexagonal network of channels, and the feature in the bottom part shows a series of parallel channels with a channel width of $9 \mathrm{~nm}$ similar to the $d$-spacing obtained from the position of the (100) peaks in the small-angle XRD patterns. The same channel width is seen in a dark-field STEM image of the same specimen of Sn-SBA-15 shown in Fig. 10.

The profile of Sn-modified SBA-15 in which the elementary composition across a particle was studied is illustrated in Fig. 11. This profile consists of 20 parallel channels.

The concentration of $\mathrm{Sn}$ along the profile shown in Fig. 11 is presented in Fig. 12, which confirms that $\mathrm{Sn}$ is distributed over the entire volume of a Sn-SBA-15 particle, although the distribution is not entirely uniform. The oscillatory character of the concentration of Sn reflects the presence of pores in the specimen. The elementary composition obtained by TEM-EDS method corresponds to $33 \%$ of $\mathrm{SnO}_{2}$ $\left(\mathrm{SiO}_{2}=100 \%\right)$ by mass, which is lower than $39 \%$ obtained from the gain of mass of sample on Sn deposition. 


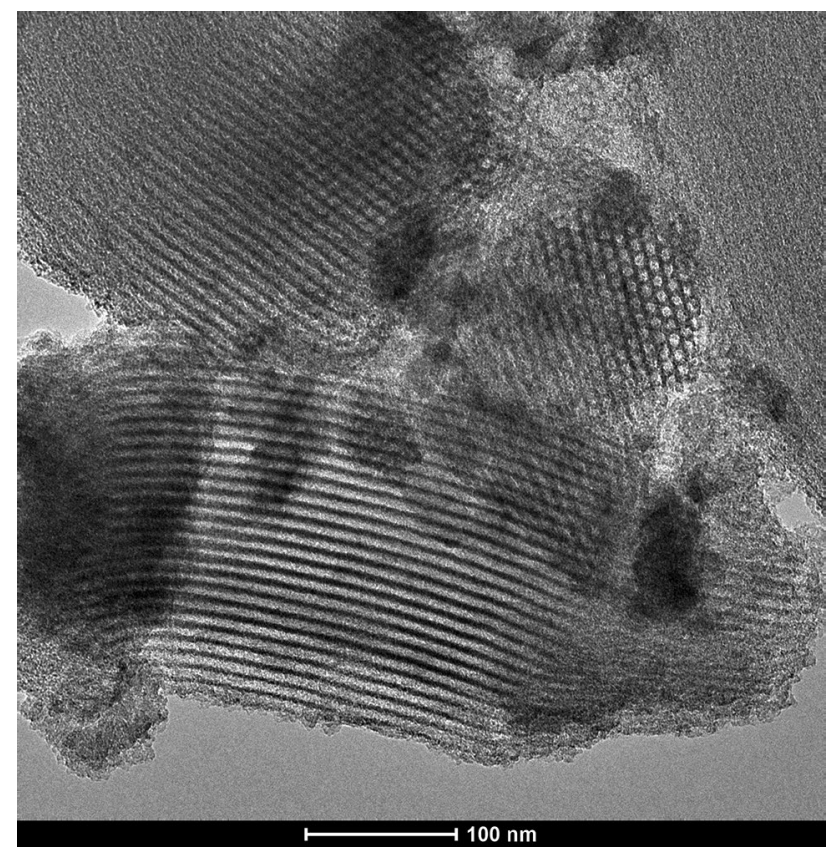

Fig. 9 Bright-field TEM image of Sn-modified SBA-15 containing $39 \%$ of $\mathrm{SnO}_{2}\left(\mathrm{SiO}_{2}=100 \%\right)$ by mass

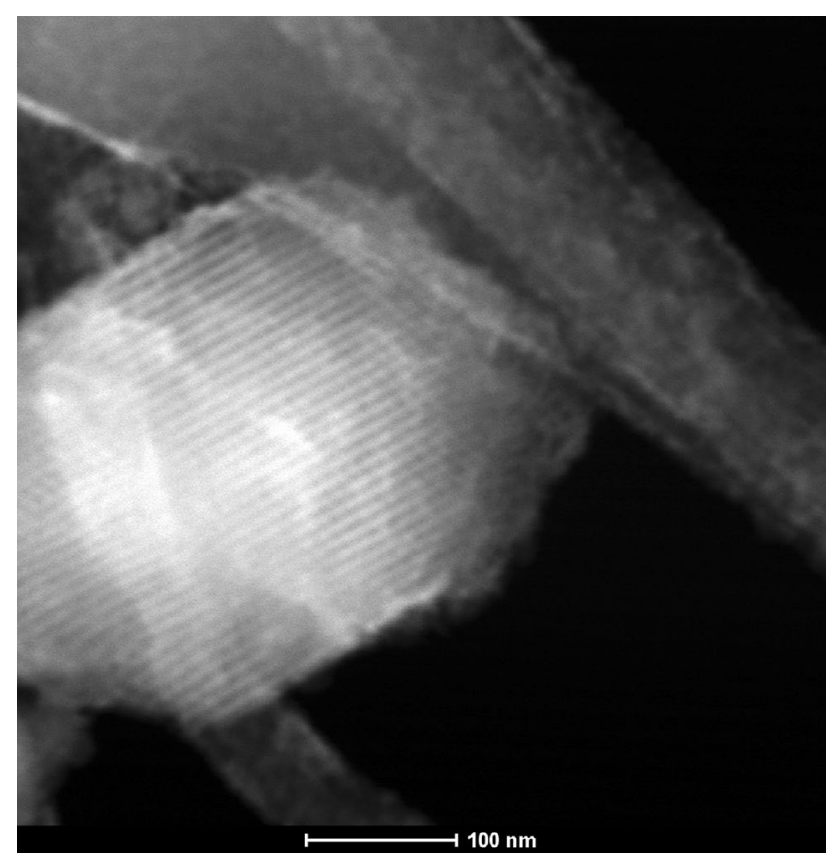

Fig. 10 Dark-field STEM image of Sn-modified SBA-15 containing $39 \%$ of $\mathrm{SnO}_{2}\left(\mathrm{SiO}_{2}=100 \%\right)$ by mass

\section{7 \Potential}

The original SBA-15 and three specimens of modified SBA-15 described in the previous sections $(\mathrm{Sn}, \mathrm{Sn}+\mathrm{Ti}$, and $\mathrm{Sn}+\mathrm{Al}$-modified) were dispersed in $10^{-3} \mathrm{M} \mathrm{NaCl}$,

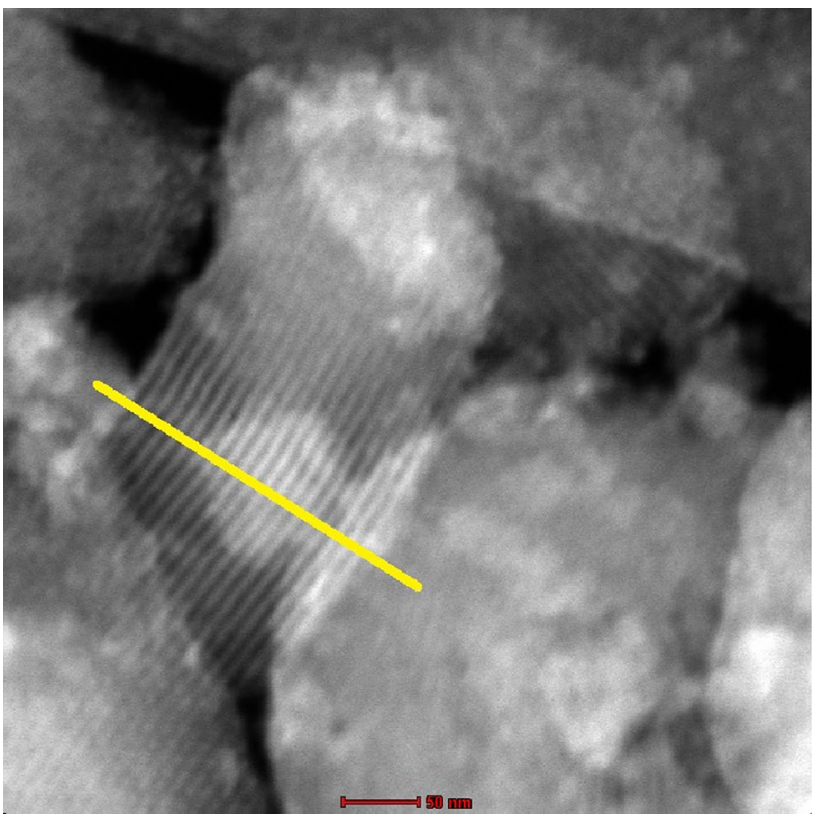

Fig. 11 Profile of Sn-modified SBA-15 containing 39\% of $\mathrm{SnO}_{2}$ $\left(\mathrm{SiO}_{2}=100 \%\right)$ by mass, in which the elementary composition across a particle was studied

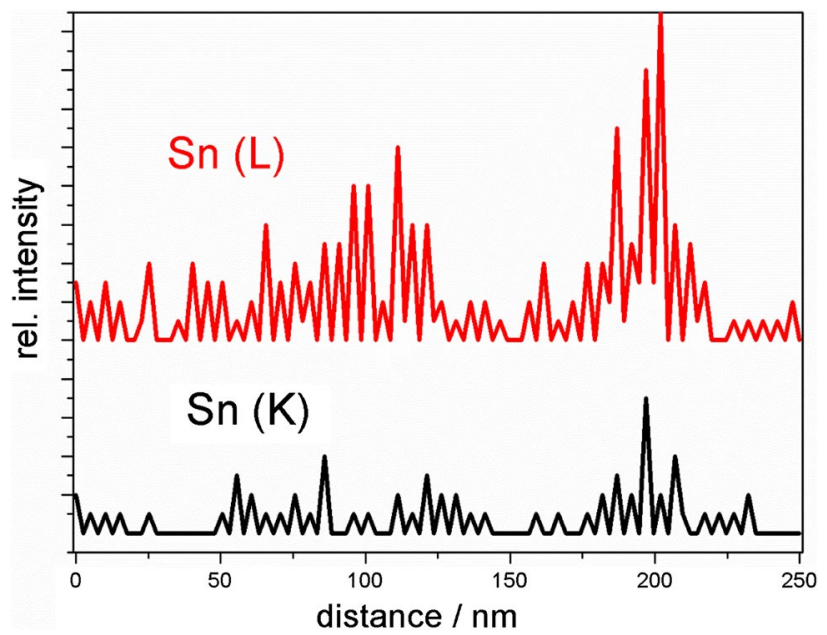

Fig. 12 The Sn concentration in a Sn-modified SBA-15 along the profile shown in Fig. 11 determined from intensity of K- and L-lines

adjusted to different $\mathrm{pH}$ with dilute $\mathrm{HCl}$ or $\mathrm{NaOH}$, and the electrokinetic potential of the particles was measured. The electrokinetic curves in Fig. 13 show an IEP at $\mathrm{pH}$ between 3 and 4 . We interpret the differences in the apparent IEP of particular specimens as a scatter of experimental points rather than as a real effect. The IEP in this range has been reported in the literature for different specimens of SBA-15 and for other silicas $[15,16]$. Apparently the metal oxides in metal-modified silicas are in the pores of SBA-15 rather than on the external surface or as separate particles. This is 


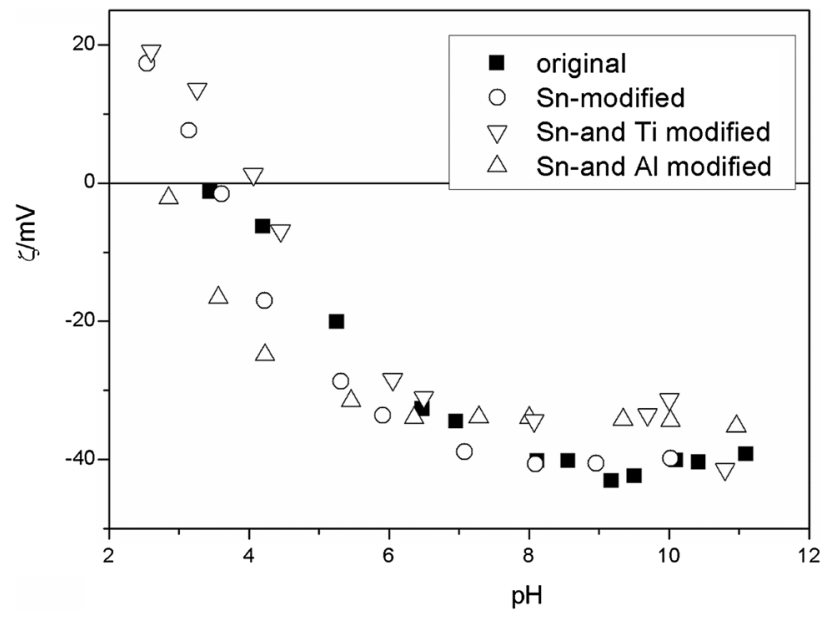

Fig. $13 \zeta$ potential of original and of metal-modified SBA-15 dispersed in $10^{-3} \mathrm{M} \mathrm{NaCl}$ at $25^{\circ} \mathrm{C}$

well-known that deposition of metal oxide on the external surface of silica leads to higher (less negative) $\zeta$ potential, and this results in a shift in the IEP to higher $\mathrm{pH}$ value. Such shifts were observed for fractions of metal oxide as low as a few per cent and even a fraction of $1 \%$ by mass. This effect is more substantial for alumina (IEP at pH 9), but it is also significant for titania (IEP at $\mathrm{pH}$ 6) while tin oxide has an IEP at $\mathrm{pH} 4.5$, that is, only slightly higher than SBA-15. The apparent IEP of Sn- and Al-modified SBA-15 shown in Fig. 13 is lower than the IEP of original silica while a shift in the IEP to high $\mathrm{pH}$ is expected in alumina-coated silicas (with respect to the original silica). The particle radius in dispersion was about $700 \mathrm{~nm}$ for all specimens shown in Fig. 13, and it was rather insensitive to $\mathrm{pH}$.

\section{Summary and further research}

Tin is deposited on SBA-15 by evaporation and condensation of vapor of $\mathrm{SnCl}_{4}$ at temperatures of $30-50{ }^{\circ} \mathrm{C}$ in a closed reactor and then by hydrolysis at room temperature. Deposition of tin depresses the SSA and total pore volume of the original silica while the effect of $\mathrm{Sn}$ on the volume of micropores is rather insignificant. The Sn-modified materials did not show presence of crystalline phases of Sn-compounds. The properties of Sn-modified silicas can be adjusted to specific application by varying the time and temperature of deposition and the geometry of the reactor. Sn-modified SBA-15 can also be used as a support for deposition of $\mathrm{Ti}$ and $\mathrm{Al}$ oxides on top of the $\mathrm{SnO}_{2}$-layer. Anatase or mixture or anatase and rutile were observed in specimens obtained by condensation of $\mathrm{TiCl}_{4}$ vapor on $\mathrm{Sn}$ modified SBA-15 followed by hydrolysis. Crystallization of titania on Sn-modified silica at low temperatures was rather unexpected, and this phenomenon needs further research. Similar materials can be obtained from porous silicas other than SBA-15 including cheap commercial products.

\section{Compliance with ethical standards}

Conflict of interest The authors declare that they have no conflict of interest.

Open Access This article is distributed under the terms of the Creative Commons Attribution 4.0 International License (http://creativeco mmons.org/licenses/by/4.0/), which permits unrestricted use, distribution, and reproduction in any medium, provided you give appropriate credit to the original author(s) and the source, provide a link to the Creative Commons license, and indicate if changes were made.

\section{References}

1. C.T. Kresge, M.E. Leonowicz, W.J. Roth, J.C. Vartuli, J.S. Beck, Ordered mesoporous molecular-sieves synthesized by a liquidcrystal template mechanism. Nature 359, 710-712 (1992)

2. D.Y. Zhao, J.L. Feng, Q.S. Huo, N. Melosh, G.H. Fredrickson, B.F. Chmelka, G.D. Stucky, Triblock copolymer syntheses of mesoporous silica with periodic 50 to 300 Angstrom pores. Science 279, 548-552 (1998)

3. M. Kumar, C. Santhosh, A. Holmen, et al., Dehydrogenation of propane over Pt-SBA-15 and Pt-Sn-SBA-15: effect of Sn on the dispersion of Pt and catalytic behavior. Catal. Today 142, 17-23 (2009)

4. B. Li, Z. Xu, W. Chu, F. Jing, Ordered mesoporous Sn-SBA-15 as support for Pt catalyst with enhanced performance in propane dehydrogenation. Chin. J. Catal. 38, 726-735 (2017)

5. J. Pang, M. Zheng, X. Li, L. Song, R. Sun, J. Sebastian, A. Wang, J. Wang, X. Wang, T. Zhang, Catalytic conversion of carbohydrates to methyl lactate using isolated tin sites in SBA-15. ChemistrySelect 2, 309-314 (2017)

6. S. Xu, D. Yu, T. Ye, P. Tian, Catalytic transfer hydrogenation of levulinic acid to gamma-valerolactone over a bifunctional tin catalyst. RSC Adv. 6, 1026-1031 (2017)

7. D. Skoda, A. Styskalik, Z. Moravec, P. Bezdicka, J. Bursik, P.H. Mutin, J. Pinkaqs, Mesoporous $\mathrm{SnO}_{2}-\mathrm{SiO}_{2}$ and $\mathrm{Sn}$-silica-carbon nanocomposites by novel non-hydrolytic templated sol-gel synthesis. RSC Adv. 6, 68739-68747 (2016)

8. T. Chen, B. Wang, Y. Li, L. Liu, S. Qiu, Hydrothermal synthesis of tin containing mesoporous silicas and their catalytic performance over Baeyer-Villiger oxidation of cyclohexanone to $\varepsilon$-caprolactone: comparison of Sn/MCM-41 and Sn/SBA-15. J. Porous Mater. 22, 949-957 (2015)

9. N.R. Srinivasan, P. Majumdar, N.K.R. Eswar, R. Bandyopadhyaya, Photocatalysis by morphologically tailored mesoporous silica (SBA-15) embedded with $\mathrm{SnO}_{2}$ nanoparticles: experiments and model. Appl. Catal. A. 498, 107-116 (2015)

10. M. Kosmulski, E. Mączka, Uptake of vapors of Cd at $480-600{ }^{\circ} \mathrm{C}$ and of $\mathrm{Zn}$ at $750-880^{\circ} \mathrm{C}$ by SBA-15. Microporous Mesoporous Mater. 246, 114-119 (2017)

11. M. Kosmulski, E. Mączka, Modification of SBA-15 with vapors of aluminum and titanium chlorides. Colloids Surf. A 535, 61-68 (2017)

12. V. Gunko, V. Zarko, V. Turov, R. Leboda, E. Chibowski, L. Holysz, E. Pakhlov, E. Voronin, V. Dudnik, Y. Gornikov, 
CVD-titania on fumed silica substrate. J. Colloid Interface Sci. 198, 141-156 (1998)

13. M.V. Landau, L. Vradman, X. Wang, L. Titelman, High loading $\mathrm{TiO}_{2}$ and $\mathrm{ZrO}_{2}$ nanocrystals ensembles inside the mesopores of SBA-15: preparation, texture and stability. Microporous Mesoporous Mater. 78, 117-129 (2005)

14. Y.J. Acosta-Silva, R. Nava, V. Hernandez-Morales, S.A. MaciasSanchez, M.L. Gomez-Herrera, B. Pawelec, Methylene blue photodegradation over titania-decorated SBA-15. Appl. Catal. B 110, 108-117 (2011)

15. M. Kosmulski, Isoelectric points and points of zero charge of metal (hydr)oxides: 50 years after Parks' review. Adv. Colloid Interface Sci. 238, 1-61 (2016)

16. M. Kosmulski, The $\mathrm{pH}$ dependent surface charging and points of zero charge. VII. Update. Adv. Colloid Interface Sci. 251, 115$138(2018)$ 